\title{
Research on Development Strategies for China's Advanced Materials Industry
}

\author{
Tu Hailing, Zhang Shirong, Li Tengfei
}

General Research Institute for Nonferrous Metals, Beijing 100088, China

\begin{abstract}
As a sector of strategic emerging industry, the advanced materials industry is vital for the socioeconomic development and security of the country. This paper describes the current status of the advanced materials industry both in China and abroad and discusses the challenges of the related enterprises. Finally, the authors propose the major development directions and put forth suggestions on government policies for promoting the advanced materials industry.
\end{abstract}

Key words: advanced materials industry; development strategy; suggestion

\section{Introduction}

"Advanced materials" are novel materials with unique properties and with traditional material compositions that display significantly increased performance or unique functionalities after processing. The advanced materials industry, which incorporates technical advances from a number of research disciplines, is a fundamental industry that supports national economic growth and forms a material basis for developments in other hightechnology industry [1].

Historically, advanced materials have facilitated the emergence of disruptive technologies that go on to drive industrial transformations. For example, the emergence of white light emitting diodes (WLEDs) led to a whole new era in the lighting industry; the replacement of cathode ray tubes with liquid crystal displays also brought about a revolution in display technologies [2]. The current emergence of organic light emitting diodes (OLEDs) [3], printed displays, and laser displays can be seen as the beginning of an entirely new generation of materials, devices, and machinery. Through years of hard work, China's advanced materials industry has made great strides, and has been improving in terms of the technological level and industrial scale. An independent and innovative system of advanced materials industry is now emerging, which is expected to provide support for high-tech industry such as the aerospace industry, rail transport, communications, biology, and new energy resources, thus overcoming technological bottlenecks and realizing great-leapforward development in China. Overall, the competitiveness of the advanced materials industry in China still has much room to improve. The enterprise-driven system of independent innovation requires urgent improvement. The availability of some of the core materials required by industry are still limited by external factors, as China's industry remains highly reliant on highend materials that are imported from overseas. Therefore, it is of strategic importance to seize opportunities to rationally plan for improvements in the capacity of the advanced materials industry, which will in turn accelerate the transformation of China's economy, strengthen its security and military capabilities, and enable the realization of environmental protection and energyreduction targets.

\section{Current state of advanced materials research and industry overseas}

In recent years, countries throughout the world have formulated plans related to advanced materials (Table 1), strengthen-

Received date: 25 May 2016; revised date: 28 June 2016

Author information: Tu Hailing, General Research Institute for Nonferrous Metals, honorary president, academician of the China's Academy of Engineering. His main research interests are in the areas of materials science and engineering. E-mail: tuhl@grinm.com

Funding program: CAE Major Advisory Project "Research on Promotion and Development Planning of China's Strategic Emerging Industry in the 13th Five-Year Plan Period" (No. 2014-ZD-7)

Chinese version: Strategic Study of CAE 2016, 18 (4): 090-100

Cited item: Tu Hailing, Zhang Shirong, Li Tengfei. Research on Development Strategies for China's Advanced Materials Industry. Strategic Study of CAE, http://10.15302/J-SSCAE-2016.04.014 
ing their R\&D in all aspects of advanced materials, and enabling market and industrial environment policies to support development. The US has announced and renewed its Strategy for American Innovation on three occasions, in 2009, 2011, and 2015. In this strategic plan, the development of clean energy, biotechnology, nanotechnology, space technology, healthcare, and other high-priority areas are all related to advanced materials. The National Strategic Plan for Advanced Manufacturing formulated in 2012 provided further support for innovations in materials technology. In 2010, the European Union formulated the Europe 2020 plan, in which three strategic priorities were proposed to help in the recovery of its economy, eliminate its chronic illness in development, and respond to global challenges. The German government has announced the Ideas, Innovation, and Prosperity: High-Tech Strategy 2020 Action Plan, of which the "Industry 4.0" is one of the most significant projects among ten so-called "Future Projects". In 2013, the United Kingdom rolled out the report on The Future of Manufacturing: a New Era of Opportunity and Challenge for the UK, which emphasizes the construction of innovation centers for new energy, smart systems, and material chemistry. In 2010, Japan launched the New Growth Strategy and A New Strategy in Information and Communications Technology. In 2009, the Republic of Korea announced the National Strategy for Green Growth and the Five-Year Plan

Table 1. Development plans related to advanced materials fields in countries around the world [4].

\begin{tabular}{|c|c|c|}
\hline $\begin{array}{l}\text { Country or } \\
\text { organization }\end{array}$ & Development plan & Related advanced materials fields \\
\hline United States & $\begin{array}{l}\text { A National Strategic Plan for Advanced Manufacturing; Regulatory } \\
\text { Reform and the US Manufacturing Sector; Advanced Manufacturing } \\
\text { Partnership (AMP); Nanotechnology Signature Initiatives; National } \\
\text { Bioeconomy Blueprint; EV Everywhere; Smarter Planet; The Federal Big } \\
\text { Data Research and Development Strategic Plan; Next-Generation Lighting } \\
\text { Initiative (NGLI); Strategies for Wideband gap, Inexpensive Transistors } \\
\text { for Controlling High-Efficiency Systems (SWITCHES) }\end{array}$ & $\begin{array}{l}\text { New energy materials, biological and medical mate- } \\
\text { rials, environment-friendly materials, and nanoma- } \\
\text { terials; materials related to advanced manufacturing, } \\
\text { new-generation information and network technology, } \\
\text { and electric vehicles; materials genome; wide-band- } \\
\text { gap semiconductor materials }\end{array}$ \\
\hline
\end{tabular}

European Union $\quad$ Strategic Energy Technology Plan; 2020 Energy Strategy; Internet of Things Strategic Research Roadmap; Europe 2020; Innovating for Sustainable Growth: A Bioeconomy for Europe; Bio-based Economy for Europe; Horizon 2020; Rainbow Project; OLED100.EU; FET Flagships

United Kingdom Low Carbon Transition Plan; UK Renewable Energy Roadmap; Innovation and Technology Center; A Strategy for Growth for the UK Marine Industry; Synthetic Biology Roadmap; UK Industry 2050

Germany Energy Concept 2050: Environmentally Sound, Reliable and Affordable Energy Supply; The High-Tech Strategy; High-Tech Strategy 2020 Action Plan; National Research Strategy BioEconomy 2030; National Electromobility Development Plan; Industry 4.0

France Roadmap for the Environmental Transition: A Roodmap; Investments for the Future Programme; Internet: Prospective 2030

Japan

New Growth Strategy; A New Strategy in Information and Communications Technology; Basic Energy Plan (2014); Declaration to be the World's Most Advanced IT Nation; Next-Generation Vehicle Plan 2010; Basic Plan on Ocean Policy

Republic of Korea New Growth Engine Industry Development Vision and Strategies; Comprehensive Nuclear Energy Promotion Plan; North Korea's Information Technology (IT) Strategy; National Fusion Technology Development Plan; The 3rd Science and Technology Basic Plan

Russia Energy Strategy for the period up to 2030; Russian Innovations Strategy 2020; Energy Strategy up to 2030; Development of Biotechnology in the Russian Federation until 2020 (BIO-2020); IT Industry Development Roadmap from 2013-2018; Development of the Electronics and Radio Electronics Industry from 2013-2025; Russia 2030: Science and Technology Foresight

Brazil Low Carbon Agriculture Plan; Brazilian National Policy in Science, Technology, and Innovation from 2012-2015; The Plan of Action on Science, Technology, and Innovation from 2011-2014

India National Action Plan for Climate Change; National Solar Mission; 12th Five-Year-Plan (2012-2017); Science, Technology and Innovation Policy 2013

South Africa
Green Paper: National Strategic Planning; Industrial Policy Action Plan; National Development Plan Vision for 2030; Integrated Resource Plan 2010-2030
Materials related to Low-carbon industry and information technology (focusing on the internet of things) industry, biological materials, graphene, etc.

Materials related to low carbon industry and high value-added manufacturing, biological materials, marine materials, etc.

Renewable energy materials, biological materials, materials related to electric vehicles, etc.

Renewable energy materials, environment-friendly materials, information materials, materials related to environment-friendly vehicles, etc.

New energy materials, energy-saving materials, information materials, materials related to advanced vehicles, etc.

Renewable energy materials, information materials, nanomaterials, etc.

New energy materials, energy-saving materials, nanomaterials, biological materials, medical and health materials, information materials, etc.

New energy materials; environment-friendly vehicles, civil aviation, and modern agriculture biological materials, etc.

New energy materials, biological materials, etc.

New energy materials, biopharmaceutical materials, aerospace materials, etc. 
as well as the New Growth Engine Industry Development Vision and Strategies. Brazil, India, Russia, and other emerging economies have implemented strategies that focus on catching up with developed nations, involving the implementation of area-specific plans for new energy materials, energy-saving materials, nanomaterials, biomaterials, healthcare materials, materials for information technology, and other similar areas, so as to strive for a coveted first-tier position of international competitiveness in these fields.

Against a backdrop of increasing globalization, the advanced materials industry generally presents the following characteristics and trends.

\subsection{High-tech developments promote continuous generational changes in materials}

The rapid rate of high-tech development has brought about new challenges and demands regarding critical base materials; at the same time, generational upgrades in materials have led to the conversion of advanced technological advances into commercial production capabilities. For example, silicon materials have played an important role in the substantial increase in microchip density and data processing speeds, as well as the continuous reduction of production costs. Although 300-mm silicon wafers are currently able to fulfill the integrated circuit requirements of the 14-nm process, 450-mm silicon wafer samples have already been produced [5]. The evolution of global silicon wafer technologies and their output by diameter are shown in Fig. 1. The development of low-temperature cofired ceramics (LTCC) was an important breakthrough, as this development made it possible to assemble large numbers of passive electronic devices on a single substrate [6]. Continued advances in materials research tech- nology have given rise to a number of emerging industry. For instance, the development of gallium nitride-based compound semiconductors has given birth to the semiconductor lighting technology; the light efficiency of white LEDs has far exceeded that of incandescent and fluorescent lamps, bringing forth revolutionary changes in the lighting industry. The steady increase in solar cell efficiencies has strongly driven developments in the renewable energies industry. Breakthroughs in the processing technologies for producing high-performance structural materials such as magnesium and titanium alloy has led to a steady decrease in production costs which has, in turn, expanded the research and applications of these materials from the exclusive realm of military and aerospace areas to high-value civilian areas as well. The development of molecular and genetic clinical diagnosis materials and machinery has augmented the early detection and treatment of major diseases such as liver cancer; the development of interventional devices has spawned minimally invasive and interventional treatment techniques, leading to a significant decrease in the mortality rates of heart disease and other diseases [7].

\subsection{Advanced materials strongly gravitate towards green and low-carbon developments}

The rise of emerging industry, epitomized by new energy industry, has triggered major changes in the electricity, construction, automotive, and communications industry. This has led to further developments in upstream industry such as the manufacture of windmills, photovoltaic modules, polysilicon, and other resource-processing industry, thus promoting the development and production of transportation and terminal products such as smart grids and electrical automobiles. Europe and the US as well as other developed countries are promoting the

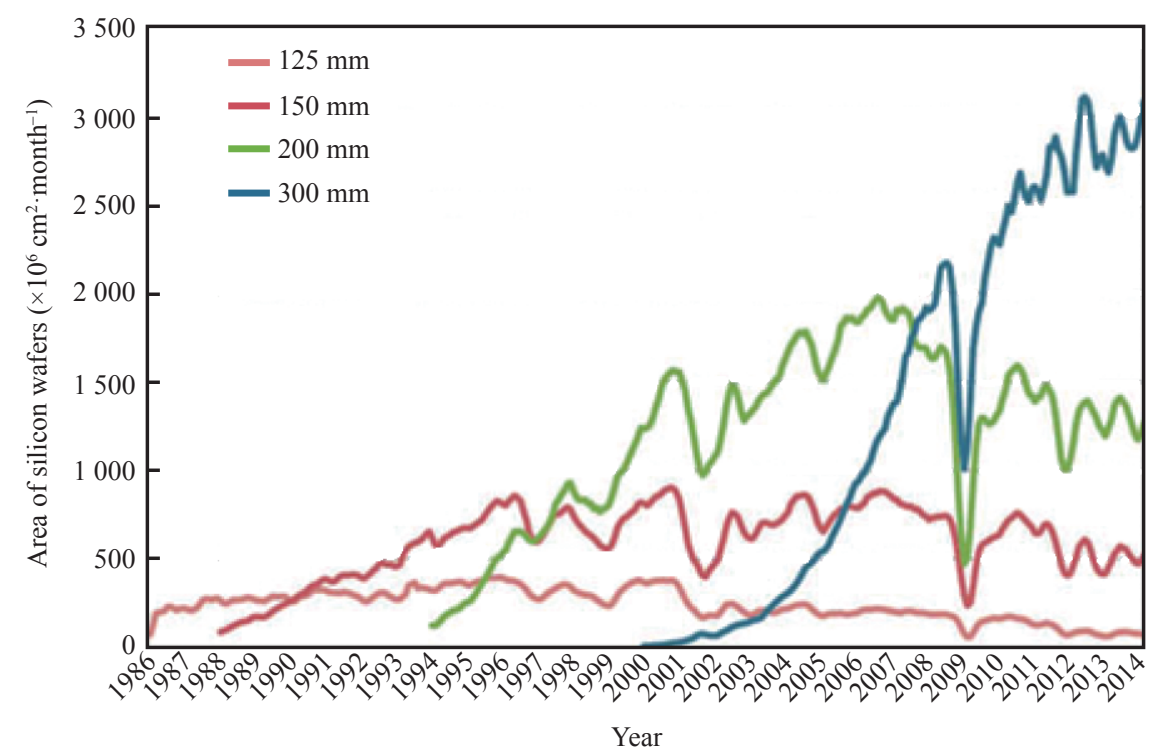

Fig. 1. Evolution of global silicon materials technology and production by regional diameter. 
development of energy-efficient buildings and the construction of photovoltaic systems through legislation. Currently, $80 \%$ of the double-glazed glass being used in Europe is made of LOW-E glass, while the usage rate of LOW-E glass in the US is $82 \%$ [8]. The installed capacity of photovoltaic systems has also increased steadily over time, as demonstrated by the growth in global cumulative installed capacity of photovoltaic systems (Fig. 2) [9]. Costs may be decreased while simultaneously increasing quality levels by improving the strength, durability, thermal adaptability and lifespan of advanced materials, and also by using the appropriate composite material design. For instance, T800 carbon fiber has a compression-after-impact (CAI) strength up to $350 \mathrm{MPa}$, a usable temperature range up to $400{ }^{\circ} \mathrm{C}$, and is heavily used in the primary structural components of large aircraft and guided missiles. The development of functional materials is moving towards miniaturization, functionalization, integration, and intelligence; the merging of nanotechnology and advanced manufacturing techniques will lead to high-performance products that are even more miniaturized, dense, and intelligent. Green and low-carbon industrialization and advanced materials technologies will become the primary direction of development in the future, as social targets such as the conservation of resources and the environment as well as public health will become more heavily prioritized alongside economic goals.

\subsection{Multinational organizations maintain a leading position in the advanced materials industry}

Presently, major international corporations occupy a dominant position in the high-value advanced materials industry, by leveraging their advantages in the areas of technological development, capital, and talent. Corporations such as Shin-Etsu, SUMCO, Siltronic, and SunEdison currently hold more than $80 \%$ of the international market share for semiconductor materials. Over $90 \%$ of the semi-insulating gallium arsenide market is held by Japanese corporations such as Hitachi, Sumitomo, Mit- subishi, and the German company FCM. Dow Chemical, GE, Wacker, Rhone-Poulenc, and a few Japanese companies basically control the global organosilicon materials market. Du Pont, Daikin, Hoechst, 3M, Ausimont, ATO, and ICI possess $90 \%$ of the world's organic fluorine materials production capacity. The US's Cree Inc. has silicon carbide substrate preparation technologies that are highly competitive in the market, while Lumileds (a US company that is a subsidiary of Philips) is the world leader in power-White LEDs; American, Japanese, and German corporations control $70 \%$ of all core patents of LED epitaxial growth and chip-preparation. The manufacture of small-tow carbon fiber is monopolized by Japan's Toray, Toho, and Mitsubishi corporation as well as the US's Hexcel Corporation; in contrast, the large-tow carbon fiber market is effectively controlled by four corporations, the US's Fortafil, Zoltek, and Aldila corporation as well as Germany's SGL Corporation. American, German, and French aluminum enterprises occupy a dominant position in the world's production and development of high-strength aluminum alloy. The Timet, RMI, and Allegen Teledyne titanium production enterprises of the US produce $90 \%$ of the total amount of processed titanium in the US, and are the main global suppliers of typical aircraft-grade titanium.

\subsection{Transformation of advanced materials research becomes a critical point of interest}

Since the beginning of the 21 st century, the developed nations of the world have come to realize that traditional trial-and-error based materials research methods are unable to keep up with the rapid development of industry and may eventually come to restrict technological progress. Therefore, there is an urgent need to transform the manner in which advanced materials are researched and developed, to accelerate the progression of advanced materials from the R\&D stage up to their deployment in actual applications. For example, the US government has stipulated the Materials Genome Initiative (MGI), an important com-

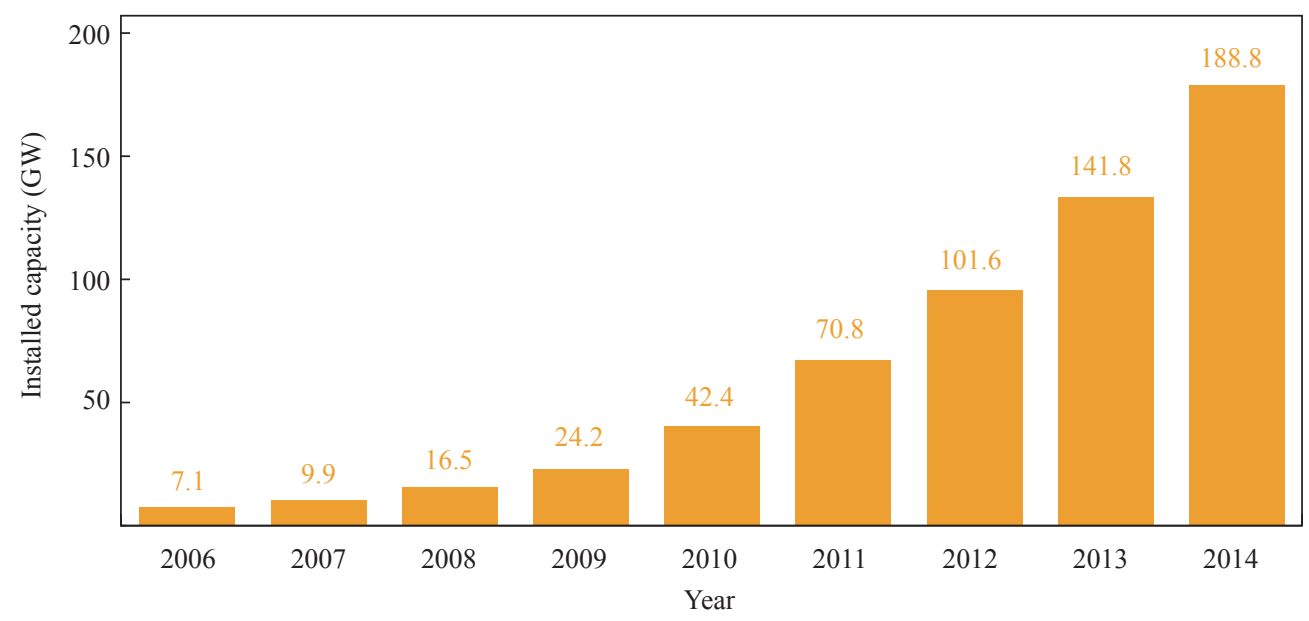

Fig.2. Cumulative installed photovoltaic capacity globally from 2006 to 2014 [9]. 
ponent of the Advanced Manufacturing Plan (AMP), namely, that the speed at which advanced materials progress from being discovered to being deployed in industry must be doubled, and the overhead costs must be decreased by at least one-half, to assure the continued development of high-end manufacturing industry that are based on advanced materials, and to maintain the US's advantage in core technological areas [10-12]; and the elements of the materials genome are shown in Fig. 3. The specific contents of the MGI include: (1) developing high-throughput computational tools and methods, reducing time-consuming and high-effort experiments, and accelerating materials design; (2) developing and propagating high-throughput materials preparation and measurement tools to enable materials validation and screening to be performed more quickly; (3) developing and improving materials database/informatics tools in order to manage the chain of processes from the discovery of a material to its deployment more effectively; (4) fostering a new collaboration model that is based on openness and cooperation.

The European Union and Japan have also initiated similar scientific plans for transforming the mode of materials research. For example, the European Union has rolled out the Accelerated Metallurgy (ACCMET) plan to satisfy demands for the following six types of high-performance materials: lightweight materials, high-temperature materials, high-temperature superconducting materials, magnetic and thermal magnetic materials, thermoelectric materials, and phase-change memory materials.

\section{Current state of advanced materials R\&D and industrial developments in China}

Since the announcement of the 12th Five-Year Plan, China's government has placed strong emphasis on the development

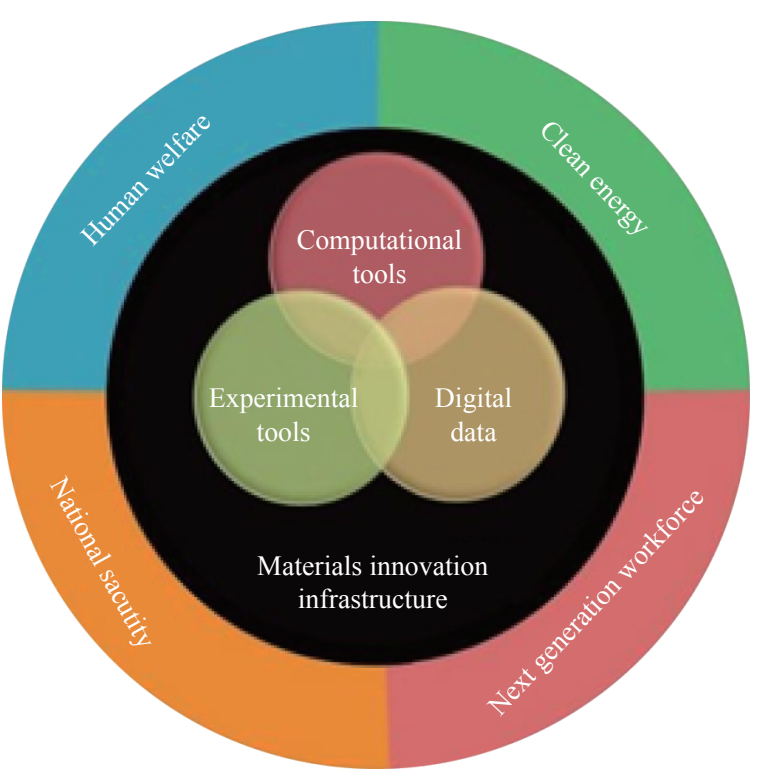

Fig. 3. Elements of materials genome. of the advanced materials industry. In accordance with the national 12th Five-Year Development Plan for National Strategic Emerging Industry and the 12th Five-Year Development Plan for the Advanced Materials Industry strategic plans, the Ministry of Industry and Information Technology (MIIT) of the People's Republic of China, National Development and Reform Commission (NDRC), and other related ministries have announced development plans related to the advanced materials industry and other strategic emerging industry (Table 2). The Ministry of Science and Technology (MOST) of the People's Republic of China has also announced specialized development plans for materials-related technologies, including the development of green manufacturing, semiconductor lighting, green building, clean coal technology, sea water desalination [13], advanced displays, national broadband network, cloud computing, medicine, service robots, high-speed trains, the informatization of manufacturing, solar and wind power generation, smart grids, and other major science and technology industrialization projects; all of these areas are related to the $R \& D$ and applications of advanced materials.

\subsection{Continues increase in the industrial scale of the advanced materials industry}

In 2015, the industrial scale of the advanced materials industry in China was approximately 1.9 trillion yuan. China's production capacity for rare-earth functional materials, advanced energy storage materials, photovoltaic materials, ultra-hard materials, special non-rusting steels, glass fiber and their associated composite materials ranks first in the world. In 2015, the production of solar energy cell components reached $23 \mathrm{GW}$, representing an increase of $20.8 \%$; the semiconductor lighting industry had taken its first step to form an R\&D and production system that encompasses upstream epitaxial materials growth and chip manufacture, mid-stream device packaging, and downstream integrated applications, with its industrial scale exceeding 500 billion yuan in 2015. In 2014, China's semiconductor silicon materials production reached $4 \times 10^{8}$ in $^{2}\left(1 \mathrm{in}^{2}=6.4516\right.$ $\mathrm{cm}^{2}$ ), which was approximately $4 \%$ of the total global production, and a $23 \%$ increase compared to 2010 . There are now more than 20 production lines for float-line-produced low-emittance and solar-control energy-saving glass, and more than 150 production lines for off-line magnetron-coated energy-saving glass, with the energy-saving glass materials industry having an industrial scale of 30 billion yuan. The production of functional rare-earth materials in China, including that of rare-earth magnetic materials [14], rare-earth luminescent materials, and rare-earth hydrogen storage materials [15], accounted for $80 \%$ of the global share. The industrial scale of the functional ceramic components had grown to 25.1 billion yuan. The industrial scale of China's advanced materials industry from 2010 to 2015 is shown in Fig. 4 [16]. 
Table 2. Development plans related to China's advanced materials industry.

\begin{tabular}{lll}
\hline Year & \multicolumn{1}{c}{ Development plan } & Related advanced materials fields \\
\hline 2010 & $\begin{array}{l}\text { Decision of the State Council on Accelerating the Fostering and Development of } \\
\text { Strategic Emerging Industry }\end{array}$ & $\begin{array}{l}\text { High-performance composite materials, advanced struc- } \\
\text { tural materials, new-type functional materials, et. }\end{array}$
\end{tabular}

2011 Guidelines for the Major Fields of High Technology Industrialization Given Priority in Development at Present (2011)

Nanomaterials, special materials for nuclear engineering, special fiber materials, membrane materials and components, special functional materials, rare-earth materials, etc.

2011 National Science and Technology Development Plan in the 12th Five-Year Plan Period

New-type functional and smart materials, advanced structural and composite materials, nanomaterials, new-electronic functional materials, high-temperature alloy materials, high-performance fiber and associated composite materials, advanced rare-earth materials, etc.

2012 Advanced Materials Development Plan in the 12th Five-Year Plan Period

Special-metal functional materials, high-end metal structural materials, advanced polymer materials, newtype inorganic nonmetallic materials, high-performance composite materials, cutting-edge advanced materials, etc.

Specialized Plan for Semiconductor Lighting Technology Development in the 12th Five-Year Plan Period; Specialized Plan for High-Quality Special Steel Semiconductor lighting materials, high-quality special steel materials, new-type lightweight alloy, membrane maTechnology Development in the 12th Five-Year Plan Period; Specialized Plan for terials, biomedical materials, lithium-ion battery materials, High-Performance Membrane Materials Technology Development in the 12th Five-Year Plan Period; Specialized Plan for the Medical Devices Technology Industry in the 12th Five-Year Plan Period; Development Plan for the Energy-Saving and New- Energy Automobile Industry (2012-2020); Development Plan for the Non-ferrous Metals Industry in the 12th Five-Year Plan Period, etc.

2013 Outline for Promoting the Development of the National Integrated Circuit Industry; Energy Development in the 12th Five-Year Plan Period; Opinions on Accelerating the Development of the Energy-Saving and Environment-Protection Industry; Action Plan for Air Pollution Prevention and Control; Several of the State Council's Opinions on the Promotion of the Healthy Development of the Photovoltaic Industry

2014 Guiding Opinions on Accelerating the Promotion and Applications of NewEnergy Automobiles; Implementation Scheme for the Upgrading of Critical Materials

2015 Made in China 2025 etc.
Large-sized silicon, photoresists, and other critical materials for integrated circuits, solar cell materials, lithium-ion battery materials

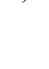

\footnotetext{
Made in China 2025
}

2016 Guiding Opinions on Accelerating the Innovative Development of the Advanced Materials Industry

\begin{abstract}
Lithium-ion battery materials, information materials, oceaneering materials, energy-saving and environmentprotection materials, advanced rail transportation materials

Special-metal functional materials, high-performance structural materials, functional polymer materials, special inorganic nonmetallic materials, advanced composite materials

Advanced basic materials: high-quality steel materials, new-type lightweight alloy materials, industrial ceramic and functional glass materials, etc;

Critical strategic materials: highly temperature-resistant and corrosion-resistant alloy, high-performance fiber, and associated composite materials, advanced semiconductor materials, biomedical materials, etc;

Cutting-edge materials: Graphene, additive manufacturing materials, smart materials, metamaterials, etc.
\end{abstract}

\subsection{Steady increase in the $R \& D$ in the advanced materials industry}

Since the beginning of this century, a number of core technological breakthroughs have been achieved through collaborations between industry and academia. This has led to significant improvements in the technical indicators of a number of important advanced materials; some of the research results from these collaborations have been widely applied in their related areas. For instance, large diameter silicon wafers have continuously improved in terms of the techniques for controlling defects, geometrical parameters, particles, and impurities. Although $300 \mathrm{~mm}$ silicon wafers are able to fulfill the integrated circuitry requirements of the $45 \mathrm{~nm}$ process, $450 \mathrm{~mm}$ monocrystalline silicon wafers have already been successfully produced. After years of development, researches of ultraviolet non-linear optical crystals such as barium metaborate (BBO) and lithium borate (LBO) have reached world-leading standards, and have also been commercialized; potassium beryllium borate-fluoride (KBBF) crystals that were developed in China are currently the only usable deep ultraviolet non-linear optical crystal in the world; the utilization of these crystals for the production of advanced scientific measurement devices was also first realized in China. The main technological indicators of Nd: YAG, Nd: GGG, and Nd: $\mathrm{YVO}_{4}$ 


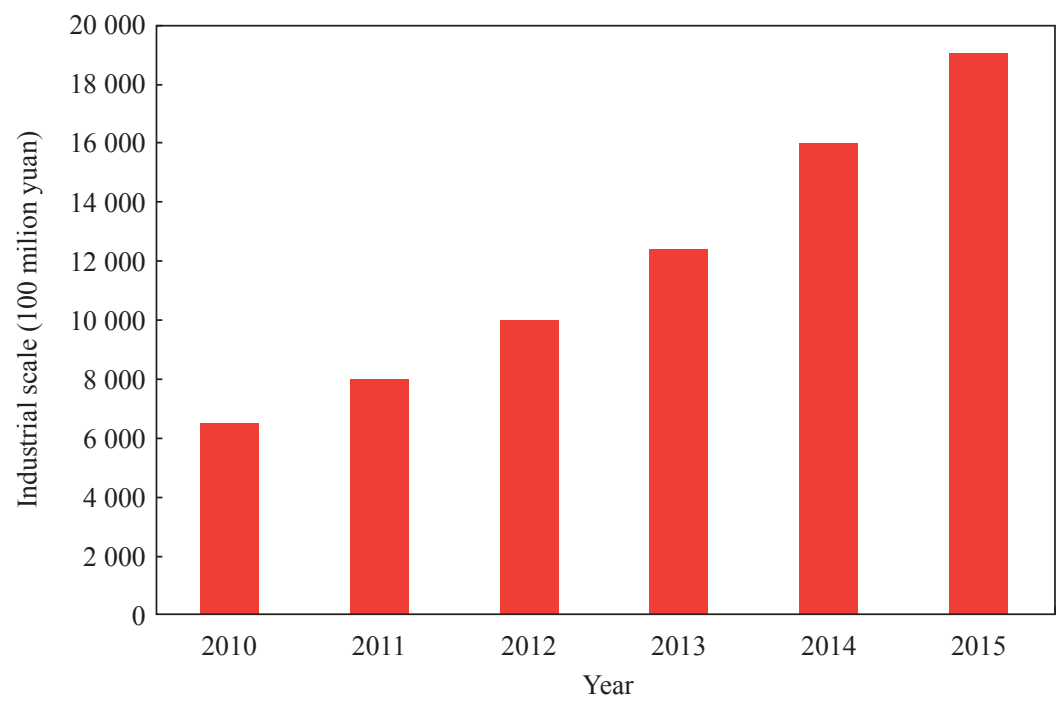

Fig. 4. Industrial scale of China's advanced materials industry from 2010 to 2015 [16].

laser crystals have also reached parity with leading international standards, and solid state lasers with kilowatt output levels have been achieved [17]. The critical technological indicators related to solar energy batteries have also reached parity with leading international standards, which has led to the generating cost of solar energy falling below 1 yuan per $\mathrm{kW} \cdot \mathrm{h}$. Lithium-ion battery cathode and anode materials as well as electrolyte are now able to fulfill the requirements of miniaturized batteries, and the supply of critical materials such as separation membranes and lithium electrolyte salts is no longer fully reliant on imports from overseas. Through the development of materials such as ultra-high molecular weight polyethylene fiber, halogenated butyl rubbers, and high-performance oil displacement polymers, the gap between China's chemical materials industry and that of developed countries has narrowed considerably. A stable level of production has been realized for the T300-grade carbon fiber, with single-line production reaching $1200 \mathrm{t}$; breakthroughs have been achieved in critical technologies for T700 and T800-grade carbon fiber, thus enabling the bulk supply of these fiber, which are now finding applications in aerospace. A rapidly solidifying spray-deposited aluminum alloy with a strength in excess of $800 \mathrm{MPa}$ and a new generation of aluminum alloy with high strength, durability, and hardenability have been developed, with the overall performance levels on par with leading international standards; cast-drawing techniques for copper strips and pipes as well as copper-aluminum composite techniques have also been independently developed and patented. The performance of sub-micron ultrafine-grained cemented carbide cutting tools has also reached the world-class levels. X65, X70, and X80 submarine cable-grade steels, thickwalled submarine gas pipelines, and thick plates for chemical tankers are now produced domestically, and the independently developed Type-2205 duplex stainless steel has been successfully applied to the construction of chemical tankers. The continuous breakthroughs in critical technologies and the increases in the types of advanced materials have strengthened the support capability of China's advanced materials including the high-end metal structural materials [18], the new-type inorganic nonmetallic materials, and the high-performance composite materials, while also improving the self-sufficiency level of the advanced polymer materials and the special-metal functional materials. The national standard of Electromagnetic Metamaterials Terminology was announced, and advanced satellite communication products that were developed by using metamaterials and radio frequency (RF) technology obtained a gold award for innovation at the first China Information Technology Expo. The production of low-cost graphene has begun, with the graphene product being applied to touchscreens, thermal films, and other information and communication related devices.

\subsection{Clear signs of agglomeration in the advanced materials industry}

In recent years, government at all levels has actively promoted the construction of the advanced materials industry bases to improve the integration of resources. This has resulted in industrial agglomeration development, obvious regional characteristics, and emerging industrial pattern of "industrial agglomeration development in the eastern coastal areas and characteristic development in the mid-west areas of China." The Yangtze River Delta has a highly robust industrial base, with excellent transportation, logistics, and industrial facilities; this has led to the agglomeration of several advanced materials industry, including aerospace, new energy resources, electronic information, and advanced chemical industry. The economy of the Pearl River Delta is primarily based on exports and has a high industrial concentration in advanced materials industry. Due to downstream-driven development, a relatively complete industrial chain has formed in this region, giving the Pearl River 
Delta a strong advantage in fields such as electronic information materials, modified engineering plastics, and ceramic materials. The Bohai Rim has a robust supporting infrastructure for technological industry, as developments in this region have been strongly driven by technological innovations; this region thus has a strong advantage in these advanced materials involving rare-earth functional materials, membrane materials, silicon materials, high-tech ceramics, magnetic materials, and special-type fiber. Additionally, these regions have also formed their own characteristics in advanced materials industry [19], including the rare earth materials industry of Inner Mongolia; the rare and precious metal materials industry of Yunnan and Guizhou; the non-ferrous metal materials industry of Guangxi; the neodymium magnet materials industry of Ningbo; the advanced chemical materials industry of Guangzhou, Tianjin, and Qingdao; the aerospace, energy, and major equipment materials industry of Chongqing, Xi'an, Jinchang in Gansu province, Xiangtan in Hunan province, Baoji in Shaanxi province, Weihai in Shandong province, and Taiyuan; the polysilicon materials industry of Xuzhou and Lianyungang in Jiangsu province, Luoyang in Henan province, and so on.

\subsection{Gradual growth in the supporting role of advanced materials in major applications and demonstration projects}

The advanced materials industry provides technological support that is necessary for the development of China's energy, resources, environment, and information fields, and serves as an important safeguard in the construction of major engineering projects and the strengthening of national defenses. Government at all levels has worked to organize and implement major application and demonstration projects, such as the "energy-saving products people-benefit project," the "10 cities 10000 lights," the "golden sun," and the "Internet of things." The results of these projects include the distribution of 30 million energy-efficient air conditioners, 3.6 million energy-efficient cars, $4 \times 10^{6} \mathrm{~kW}$ energy-efficient motors, 160 million energy-efficient lamps, and more than 1.6 million LED lamps, as well as the construction of over 340 photovoltaic electricity projects. Through demonstration projects such as the " 10 cities 1000 vehicles" and with the support of related government policies, the production of China's new energy vehicles reached 379000 in 2015, which was the highest in the world. The new-energy vehicles market is expected to reach an ownership level of 5 million in 2020, with the hope that this will further increase to 15 million vehicles in 2030. Membrane materials have already been deployed in desalination works, which allowed the first steps to be taken towards the production of fresh water through the reverse osmosis of seawater, and will become an important component of the system that provides fresh water to the coastal regions of China. High-performance structural materials, as represented by non-ferrous metal structural materials, special steel materials as well as refractory metals superalloy, carbon fiber, and associated composite materials [20], are indispensable critical materials for high-tech development, and have contributed greatly to the implementation of major engineering projects such as high-speed rail, large aircraft, manned space flight, moon exploration, EHV power transmission, and deep sea oil and gas exploitation.

\section{Developmental trends and characteristics of the advanced materials industry [21]}

The development of advanced materials characteristically proceeds in the direction of structural and functional integration, material and device integration, nanoscale miniaturization, material compositing, and environmental sustainability. These characteristics have had a significant influence on the development of high-Mach-number aircraft, micro- and nano-electromechanical systems, advanced medical drugs, high-end cosmetics, and new-energy batteries.

Advanced materials play an important role in scientific and technological progress. For instance, high-performance special steels and superalloy offer optimum choices for high-speed rail wheels and aircraft engines; ultra-high strength aluminum alloy are a critical structural material for the construction of large aircraft frames; and high-strength, high-toughness, and corrosionresistant titanium alloy are indispensable materials for marine engineering and the hulls of the Jiaolong deep-submergence vehicles.

The deep integration that occurs when advanced materials are combined with each other or with other scientific and technological disciplines is one of the characteristics of advanced materials development. For instance, the combination of high- $k$ and ultra-high- $k$ dielectric materials with new types of metal gate transistors has pushed the development of integrated circuits towards technological processes as low as $45 \mathrm{~nm}$ and below. The amalgamation of perovskites and organic materials has given rise to a new and promising type of solar cell. The use of smart materials in $3 \mathrm{D}$ printing has led to $4 \mathrm{D}$ printing techniques. The combination of organic composite materials, bioactive materials, and clinical medicine has led to the creation and development of "electronic skin" and tissue regeneration technologies. Carbon fiber and composite materials are already being deployed in aerospace and advanced vehicles. Compound semiconductor materials have facilitated the use of terahertz technologies in environmental monitoring, medicine, and anti-terrorism. Metamaterials [22] that combine with advanced materials by the microstructures have led to astonishing results in the fields of electromagnetism and optics. Flexible electronic materials, new energy materials, and biomedical materials have excellent prospects in the market. Research into spintronic materials and ironbased superconductors is currently in its ascendancy. Variable resistance, phase change, and magnetic storage materials are expected to transform traditional semiconductor storage devices. 
Fullerenes, graphene, and carbon nanotubes have opened up prospects of carbon-based materials; the success of the graphene peeling process has led to a boom in research into $2 \mathrm{D}$ materials such as molybdenum disulfide, stanene, phosphorene, silicene, and germylene [23,24].

High-throughput calculations, high-throughput synthesis and characterization, as well as large databases, have accelerated the design, performance prediction, and production process simulation of advanced materials. This has significantly shortened the development period of materials and reduced production costs, thus transforming the modes of R\&D and industrialization of advanced materials, with low-rhenium superalloy and the newtype lithium-ion battery electrode materials being excellent examples. Most recently, the anomalous Hall Effect predicted by high-throughput calculations has been experimentally verified using topological insulator materials [25].

The R\&D and production of advanced materials places great importance on energy savings and environmental conservation and renewability, and usually includes a life-cycle assessment. This has resulted in the replacement of toxic materials with non-toxic alternatives, reductions in the use of middle and heavy rare earth minerals, the use of membrane materials for seawater desalination, the use of energy-saving materials in buildings, R\&D of biomaterials, and the implementation of the "short, small, thin, and light" philosophy in development. Low-carbon and environmentally friendly processing techniques have also developed at a rapid pace as a consequence.

The integration of military and civilian markets through dual-application products is one of the development trends of advanced materials. Wide-band-gap silicon carbide and Gallium nitride based next-generation energy-efficient and high-power radio frequency devices will become high-potential, high-end electronic products for both the civilian and military markets.

Besides that, the new methods, new techniques, and new equipment for the preparation of advanced materials are imperative, and should be developed in a coordinated manner. The industrialization of the research results of advanced materials has been accelerating, while steadily decreasing in cost. The R\&D, engineering, and industrialization of advanced materials are set to the focus for research units, universities, enterprises, governments, and the markets of countries throughout the world.

\section{Existing obstacles to the development of China's advanced materials industry}

Since the reform and opening-up of China, China's advanced materials industry has made great strides, steadily increasing in scale and improving in technological level, and has already been a world leader in certain fields. Industrial agglomeration zones are being set up at increasing rates to actively improve the macroenvironment for further development, and to lay down a solid foundation for the next steps in development. The advanced materials industry has been one of the four main pillars of China's Strong Industrial Base initiative, and the Made in China 2025 plan will also incur an urgent demand for large amounts of advanced materials [26]. As a whole however, there is still a large gap between China's advanced materials industry and that of developed nations, as the development process in China still has a number of contradictions and issues that are currently bottlenecking the development of the new materials industry. These are presented in the four aspects described below.

\subsection{Lack of top-level designs and overall coordination, and tendency towards redundant low-level construction}

Given the industrial plans that have been announced for the advanced materials industry by regional governments, the top-level designs for the industrial distribution related to advanced materials do not appear to be sufficiently thorough or specific. Many regional industrial plans have not been rationally differentiated to fully leverage their respective regional advantages, which has resulted in severe convergence. In some industry, there is a lack of coordination between the upstream and downstream markets, with upstream products not being fully utilized by downstream industry, resulting in upstream overproduction and a shortage of effective supply in the downstream market. Furthermore, investments that blindly follow market "fashions" and trends have not been curbed effectively, which will not only result in redundant construction and overproduction, but also threaten the sustainability of industrial development.

\subsection{Lack of originality, weaknesses in the development of common technologies and support capacity, and lack of self- sufficiency in high-end products}

China's advanced materials industry suffers from a lack of originality in innovation, as there is a lack of deep exchanges between disciplines and original theoretical research. Although innovations are primarily driven by enterprises, there is a relative lack of participation in innovative research, and the production techniques applied are often based on imitation. The critical technologies generally available to the industry exhibit low self-sufficiency, and the industry also possesses a relatively small number of patents, the critical components and core parts of this sector are thus reliant on external parties. The industrial common technologies form the basis for improving the industry's capacity of independent innovation. As the majority of domestic industry do not have specialized R\&D organizations for industrial common technologies, the state of R\&D in these technologies is currently sub-optimal; the lack of good resource allocation mechanisms as well as sustained and effective investment in the $\mathrm{R} \& \mathrm{D}$ of industrial common technologies has made it impossible for independent innovation to be sustained. Additionally, China's 
advanced materials industry has not yet formed large systems or material designations with indigenous intellectual property right; the national and industrial standards for basic raw materials, the unified design specifications, and the control specifications for materials, technique, and quality are also generally incomplete; there is a lack of a common database for the structural design, manufacture, and evaluation of advanced materials that satisfies industrial standards, and an absence of basic supporting systems for the industry. Most enterprises are still trapped within a loop in which materials are repetitively imported for processing and production, which has led to the lack of genuine local-production elements in the production of "Made in China" products, and are thus reliant on their distress selling and low level competition to find their way, this has had a significant restrictive effect on the leapfrog-style development of the advanced materials industry.

\subsection{Scattered investment in advanced materials with incomplete industry chains}

Some of the industrial structures of China's advanced materials field have not been designed with sufficient rationality, and investments in this industry tend to be highly fragmented and uncoordinated as a result, the lack of direction of such investments has prevented the "chain effects" that could have pushed the development of this industry one step further. The government is generally more willing to invest supportive funds into stateowned enterprises and research institutes, although private enterprises are encouraged to participate in competition from policy perspective; they are facing numerous obstacles that prevent their participation in major national projects from an operational perspective. Furthermore, those enterprises that drive development in the advanced materials industry are usually relatively small in scale, and other issues facing this industry include the absence of an overall development plan, fragmented investment, a low conversion rate (from research results to commercial products), and incomplete industry chains. In some industry, advanced materials enterprises mainly congregate in the mid-to-downstream sectors, causing the weak industrial supporting ability.

\subsection{Difficulties that policy and safeguarding mechanisms face in meeting development demands of the advanced materials industry}

There is a certain level of reliance on old and outdated management methods in the critical sectors and focus areas of the advanced materials industry, which has led to difficulties in the introduction of innovative products in the market. Long administrative examination and approval periods (especially for medical products) hinder the enterprises' enthusiasm of innovation. There are few financial safeguard mechanisms to support the development of high-risk projects. There are also shortcomings in market-access mechanisms. Additionally, a service platform for the advanced materials industry has yet to be established, and existing venture capital and intermediary services are unable to fulfill the requirements of enterprises' innovation and entrepreneurship. The conversion of advanced materials research results into commercial products and the associated engineering processes require substantial investment, but given that the engineeringoriented diversified investment and financing systems and intermediary service systems are still inadequate, innovation and industrial development in the advanced materials field have been somewhat restricted.

\section{Critical direction of cultivation and development in China's advanced materials industry}

In the face of the next global revolution in science and technology, global industrial transformations, and a critical window of opportunity where China's socio-economic development will be at an important juncture, there is a need to accelerate the technological breakthroughs in advanced materials research. Emphasis must be placed on the innovation and the application of disruptive and superseding technologies, critical areas that support socio-economic development and the major needs of national defense industry should be selected, while an environment that is suitable for industrial development should be created to promote industrial structure upgrading and to form an optimal industry ecology, with the goal of driving sustainable socio-economic development being realized.

The focus areas and technologies for cultivation and development in advanced materials industry, as voted by experts in the field, are listed in Table 3. The main focus of cultivation and development should be the improvement of the quality of products and the transformation of development approach towards emphasizing quality and profitability, so as to improve the core competitiveness of the industry; more attention should be paid to the development of resource-based advanced materials, as well as the integration of this development with ecological conservation; it is very important to coordinate the development of national focus areas, such as next-generation information technologies, new energy resources and the environment, biology and health, and intelligent manufacturing, so as to provide the advanced materials support for realizing the innovation-driven development strategies; more focus should be placed on the systematic development of the entire-chain industrial system that integrates the $\mathrm{S} \& \mathrm{D}$, design, production, and applications of advanced materials to strengthen the industrial sustainable development capacity; for the realization of green and sustainable development, greater attention should be paid to energy consumption and the costs incurred by the advanced materials industry to establish technological, production, and profitability systems that are resource-saving and environmentally friendly. 
Table 3. Focus areas for cultivation and development in the advanced materials industry.

\begin{tabular}{|c|c|c|c|}
\hline No. & Focus areas & No. & Focus areas \\
\hline 1 & Large-diameter silicon and silicon-based materials & 34 & $\begin{array}{l}\text { High-performance synthetic rubber materials and their appli- } \\
\text { cations }\end{array}$ \\
\hline 2 & Wide-band-gap semiconductor material technologies & 35 & Conductive polymer materials \\
\hline 3 & $\begin{array}{l}\text { High-power lasers and non-linear optical crystals, devices, and } \\
\text { application technologies }\end{array}$ & 36 & Tissue-inducing biomaterials and tissue engineering products \\
\hline 4 & $\begin{array}{l}\text { Preparation techniques for graphene and other carbon-based } \\
\text { nanomaterials }\end{array}$ & 37 & Carriers and systems for targeted and controlled drug release \\
\hline 6 & Next-generation materials' storage and preparation technologies & 39 & $\begin{array}{l}\text { Minimally invasive and interventional treatment technologies } \\
\text { and devices }\end{array}$ \\
\hline 7 & High-performance sensor and detector materials technologies & 40 & Nano-biomaterials and soft nanotechnology \\
\hline 8 & Printed electronics manufacturing technology & 41 & Implantable microelectronic devices \\
\hline 9 & Semiconductor-based spintronic materials and devices & 42 & Smart implantable prosthetic limbs \\
\hline 10 & $\begin{array}{l}\text { Low-cost and high-performance scale manufacture technologies } \\
\text { for polysilicon production }\end{array}$ & 43 & Biomedical sensor materials and devices \\
\hline 11 & $\begin{array}{l}\text { High-temperature photothermal materials technology and its } \\
\text { industrialization }\end{array}$ & 44 & Bio-based materials \\
\hline
\end{tabular}

12 Control technologies for the performance, composition, and processing of large and high-quality zirconium alloy tubes and the next-generation $\mathrm{SiC}$ tubing

13 Preparation techniques for the industrialization of laminated light-concentrating thin-film solar energy cells

Preparation techniques for high-capacity, high-voltage, and longlife lithium-rich solid solutions of cathode materials

Preparation techniques for high-capacity, long-life siliconcarbon/alloy-based anode materials

Research and applications of solid-state/high-pressure mixed hydrogen storage systems as a hydrogen source for automobiles

Multi-functionalization and compound technologies for the coated glass and solar control energy-saving coated glass

High-performance separation membrane materials

Solid-oxide fuel cell materials

Highly effective carbon dioxide electrochemical catalytic reduction technology

Solar cells for space applications

High-performance special ceramic fiber and its associated preparation techniques

Thin-walled, large, and complex-shaped ceramic components and special ceramic powders used in $3 \mathrm{D}$ printed additive manufacturing, and their associated preparation techniques Green, low-cost preparation techniques for ultrathin multi-layer ceramic components and ceramic-based composite materials Design and batch preparation techniques for new-type hightemperature-resistant/thermal-shock-resistant/corrosion-resistant advanced ceramic materials

$\mathrm{R} \& \mathrm{D}$ and batch production techniques for ceramic-based composite materials used in aerospace engines

Preparation techniques for new-type high-performance fireresistant materials

Preparation techniques for high-performance glass fiber and associated composite materials

Preparation techniques for long-life and high-performance concrete

Preparation techniques for high-performance carbon fiber (high strength, high strength intermediate modulus, high modulus, high modulus and high strength) and the associated resin-based composite materials

31 Low-cost preparation techniques for carbon-based/carboncomposite materials

Preparation techniques for high-performance organic fiber and associated composite materials

Preparation techniques for low-cost and green preparation of lightweight aluminum, magnesium, and titanium metals

Special alloy such as high-performance high-temperature alloy, and their associated preparation techniques

Steels for ultra-supercritical applications and their associated preparation techniques

High-performance bearing steel, gear steel, die steel, tool steel, and steel for critical components, as well as their associated preparation techniques

Steels for rail wheels and their associated preparation techniques

High-performance copper and copper-alloy materials

High-purity rare-earths and their associated preparation techniques

A next-generation rare-earth materials preparation and processing, as well as structure and performance control techniques based on multi-scale modeling and simulations.

High-end rare-earth functionalized nanomaterials and preparation techniques for scale production

Rare-earth magnetic sensors and magnetostrictive materials and devices

Design, preparation and application techniques for rare-earth metal-based composite materials

Service evaluation and safety control techniques for critical functionalized rare-earth materials in major engineering projects

High-performance fiber materials and their associated preparation techniques

Highly effective and high-temperature insulation materials and their associated preparation techniques

Ultra-wide-band-gap semiconductor materials and their associated preparation techniques

Superconducting materials and their associated preparation techniques

Technologies for high-efficiency usage, and the safe and green preparation of energetic materials

Establishment of a platform for the testing of materials, material computations and a materials performance database. Smart textile materials and their associated preparation techniques

Metamaterials and their preparation techniques

Quantum dot infrared materials and devices 


\section{Governmental policies to accelerate the development of China's advanced materials industry}

Faced with the demands of information technologies, highend equipment and its manufacture, green and low-carbon developments, biological industry, digital creative industry, and major engineering projects, it is necessary to strengthen efforts to improve quality and efficiency of the advanced materials industry, and its collaborative applications, to further improve the industry's basic supporting capacity, thus integrating advanced materials into the global high-end manufacturing supply chain. It is also important to further improve the degree of selfsufficiency of critical advanced materials and to form a series of forward-looking innovation achievements by setting the stage for R\&D into cutting-edge advanced materials, thus accelerating the transformation of China from a big country in materials consumption to a world leader in materials production. To achieve these goals, we offer a few suggestions below.

\subsection{Improve top-level designs and industrial policies}

It is necessary to increase national investment in basic research of advanced materials, and to pay attention to the cutting-edge advanced materials that are still in the developmental stages, so as to make the appropriate arrangements in advance. Focus should be centered on achieving a breakthrough in engineering problems related to the industry development of advanced materials to improve the basic support of the advanced materials industry. Policies and legislative systems that are beneficial for driving progress in the advanced materials industry need to be perfected more quickly, and guidance catalogue and investment guideline for advanced materials industry development should be drawn up to establish a system of standards for the related technological disciplines and to complete industrial chain, innovation chain, and funding chain. In accordance with the principle that investors should be fully responsible for their investments, the return rate of state-owned capital investments should be monitored more closely; the focus of national support in critical industry should be highlighted to prevent "investment fragmentation" and to enable efforts to be focused on nurturing and creating high-quality, branded advanced materials products made in China.

\subsection{Utilize the role of markets in allocating resources, to establish an enterprise-based development system}

Based on the affirming the strategic guiding role of the government in the development of the advanced materials industry, a market environment that enables advanced materials-related enterprises to operate independently and to compete fairly should be created without delay. Industry-academia collaborations may then be strengthened by making enterprises the primary invest- ment subjects and the main users of research results. This would make full use of the role of the market in allocating resources, thus improving the effectiveness and fairness of resource allocations. Powerful partnerships between dominant enterprises should be promoted for the implementation of cross-regional mergers and acquisitions, as well as overseas acquisitions and investments cooperation to increase industry concentration and to accelerate the establishment of enterprise groups with international competitiveness. The historical opportunity to accelerate industrialization in China should be seized to nurture and expand consumer markets of advanced materials, especially in the middle and high-end market. This will drive developments through consumer demand, promote increases in the scale and standards of enterprises, accelerate supply-side structural reforms, expand collaborations with international production enterprises in all aspects, and drive the rapid integration of advanced materials into the supply chains of global high-end manufacturing.

\subsection{Strengthen establishment of supporting structures and systems, to consolidate foundations for development}

R\&D support for the preparation of advanced materials and automated test facilities should be further increased, and efforts should be focused on improving the quality of products, reducing the costs of core manufacturing equipment, developing new forms of low-cost production techniques and the associated supporting technologies, and deeply developing intelligent manufacturing technologies for the advanced materials. A development platform for materials design and performance testing under extreme conditions should be established, and an index system about the in-service performance of materials and life-cycle cost should be drawn up to improve the applications of materials at all levels in China. A publicly accessible database for the structural design, production, and evaluation of advanced materials should be established, and with downstream applications in mind, a materials standards system specific to China and in-line with international standards should also be built [27]. An intellectual property system for the advanced materials industry should be prioritized and researched from a strategic perspective, so as to strengthen intellectual property protection and to encourage original and integrated innovations in the R\&D of advanced materials [28] and gradually form material designations and systems with indigenous intellectual property right. Collaborations for application and piloting demonstrations should be initiated and a platform for collaboration in applications should also be set up, so as to drive structural reform and upgrading of the advanced materials industry.

\subsection{Strengthen talent development and actively bring in innovative talentss}

Development strategies for innovative talentss need to be 
implemented to support enterprises in strengthening their innovation capacity and to increase training of innovative talentss for the advanced materials industry. High-level technology and management talents abroad should also be introduced so as to establish incentives and competition mechanisms for the development of innovative talents. At the same time, advanced materials enterprises should be encouraged to actively carry out international collaborations and exchanges and to bring in advanced technologies and management experiences from overseas. This can improve enterprise management levels. The role of universities, research institutes, and industrial associations should be given full play to establish an expert system for the advanced materials, thus improving communication and exchanges in the development, production, and applications of the advanced materials. This expert system should periodically deliberate and assess the R\&D and application needs of the advanced materials both in China and overseas, and play the role of think tanks to provide advice regarding to critical issues that require a focus on the development of the advanced materials industry.

\section{References}

[1] Shi C X. Reflections on the construction of China's "New Material Industry System" [J]. Journal of Engineering Studies, 2013, 5 (1): 5-11. Chinese.

[2] Shuji N. Future technologies and applications of Ill-nitride materials and devices [J]. Engineering, 2015, 1 (2): 161. Chinese.

[3] Duan L, Qiu Y, OLED lighting and OLED active display material and device [J]. Advanced Materials Industry, 2011 (2): 20-26. Chinese.

[4] China Institute of Engineering Development Strategy. 2014 report on the development of China's strategic emerging industry $[\mathrm{M}]$. Beijing: Science Press, 2013. Chinese.

[5] Tu H L. $450 \mathrm{~mm}$ silicon wafers are imperative for moore's law but maybe postponed [J]. Engineering, 2015, 1 (2): 162-163. Chinese.

[6] Li L T. Development in functional ceramic materials and their applications [J]. Journal of the China's Ceramic Society, 2010 (5): 107-110. Chinese.

[7] Zhang X D, Wang B T. The rise of biological materials science and industry in China [J]. Advanced Materials Industry, 2009 (10): 92-95. Chinese.

[8] Nie Z R, Gao F, Gong X Z, et al. Recent progress and applications of materials life cycle assessment in China [J]. Progress in Natural Science: Materials International, 2011, 21 (1): 1-11.

[9] China New Energy Chamber of Commerce. Annual development report on world energy (2015) [R]. Beijing: 2015. Chinese.

[10] Chen L Q. The materials genome initiative and advanced materials [J]. Engineering, 2015, 1 (2): 169.

[11] Gerbrand C, Kristin P. With supercomputers and the equations of quantum mechanics, scientists are designing new materials atom by atom, before ever running an experiment $[\mathrm{J}]$. Scientifc American, 2013 (5): 36-40.

[12] Anubhav J. The materials project: A materials genome approach to accelerating materials innovation [J]. APL Materials, 2013, 1 (1): 2166-2176

[13] Xu N P, Gao C J, Jin W Q. Innovations of membrane science and technology in China [J]. Engineering Science, 2014, 15 (12): 5-9. Chinese.

[14] Li W, Zhu M G. The foundations theory and industrial technology and equipment of China's rare earth permanent magnet [C]. The Forum of China Electromagnetic Materials and Device. Tunxi, 2012. Chinese.

[15] Jiang L J. Study and applications of rare earth hydrogen storage materials [J]. Rare earth Information, 2011 (9): 4-6. Chinese.

[16] Ministry of raw materials industry division of Ministry of Industry and Information Technology of the Peopled Republic of China. Annual development report of China new material industry [M] Beijing: Publishing House of Electronics Industry, 2014. Chinese.

[17] Wang J Y, Wu Y C. Progress of the research on photo electronic functional crystals [J]. Materials China, 2011, 29 (10): 1-12. Chinese.

[18] Xu K D. China's special steel production over the past 60 years [J]. Iron and Steel, 2014, 49 (7): 2-7. Chinese.

[19] China Center for Information Industry Development. White paper on China's new materials industry map (2012) [R]. Beijing: 2012 Chinese.

[20] Bao J W, Chen X B. Advance in high temperature polyimide resin matrix composites for aeroengine $[\mathrm{J}]$. Journal of Aeronautical Materials, 2012 (6): 1-13. Chinese.

[21] Tu H L. Developing advanced materials to meet the scientific and technological revolution $[\mathrm{J}]$. Science and Technology Review, 2014, 32 (34): 1. Chinese

[22] Liu R. Broadband ground-plane cloak [J]. Science, 2009, 323 366-369.

[23] Geim A K, Novoselo K S. The rise of grapheme [J]. Nature Materials, 2007 (6): 183-191.

[24] Geim A K. Graphene: Status and prospects [J]. Science, 2009, 324 $1530-1534$

[25] He K, Wang Y Y, Xue Q K. Quantum anomalous Hall Effect [J]. National Science Review, 2014 (1): 38-48.

[26] Lu Y X. Accelerate industrial foundation, consolidate the foundation of manufacturing power $[\mathrm{M}]$. Strengthen the foundation for industry development. Beijing: Publishing House of Electronics Industry, 2016. Chinese.

[27] Zhang G, Zhang C, Yang Q H, et al. Foundation of quality and technology. Strengthen the foundation for industry development [M]. Beijing: Publishing House of Electronics Industry, 2016. Chinese.

[28] Gan Y, Yan J L. Industrial technology innovation system. Strengthen the foundation for industry development $[\mathrm{M}]$. Beijing: Publishing House of Electronics Industry, 2016. Chinese. 